\title{
Assessing Factors Influencing Farmers Adoption of Improved Potato Varieties in Malawi
}

\author{
Kapalasa Eliya ${ }^{1}$, Demo Paul ${ }^{1}$, Nyekanyeka Ted ${ }^{2}$, Okero Julius ${ }^{3}$ \\ ${ }^{1}$ International Potato Center, Lilongwe, Malawi \\ ${ }^{2}$ United Nations Development Program, Lilongwe, Malawi \\ ${ }^{3}$ International Potato Center, Kampala, Uganda
}

Email address:

E.Kapalasa@ cgiar.org (K. Eliya)

\section{To cite this article:}

Kapalasa Eliya, Demo Paul, Nyekanyeka Ted, Okero Julius. Assessing Factors Influencing Farmers Adoption of Improved Potato Varieties in Malawi. International Journal of Economy, Energy and Environment. Vol. 4, No. 1, 2019, pp. 1-10. doi: 10.11648/j.ijeee.20190401.11

Received: August 15, 2018; Accepted: September 1, 2018; Published: February 28, 2019

\begin{abstract}
Cultivation of improved varieties is one way of increasing productivity of many crops especially in developing countries where there is pressure of land due to high population growth. Adoption studies have proved to be helpful in giving the picture of the performance of technologies amongst users like farmers and in line with this the study was carried out to assess the factors that influence a farmer to adopt improved potato varieties using cross-sectional data that was collected from 300 households by the International Potato Center (CIP) in 2013. The study used a Hurdle Poisson model to effectively assess the socio-economic and demographic characteristics that influence farmers to adopt improved potato varieties. The results of the study show that amongst the household socio-economic characteristics that were included in the model, age of the household head and farm size were significant at 5 percent level of significance whilst access to information through extension agents and distance to the market were the institutional factors that significantly influence a farmer. The results further show that the variety characteristics that were significant in influencing adoption of improved potato varieties included high yield, early maturity and larger tuber size that were preferred variety characteristics. Results of the decision on how many potato varieties individual farmer decides to grow shows that age of the household head, access to information and varieties that are high yielding had a significant influence. To increase adoption of recommended potato production practices, it was recommended that extension agents should be well involved in disseminating these production practices by using open field days, demonstration and control plots to encourage farmers to adopt the production practices. Secondly, the study also recommended that Government and other stakeholders need to also invest in extension service in sensitizing potato farmers in key potato production areas especially on production practices that have potential to increase level of adoption as well as farmer's productivity and income.
\end{abstract}

Keywords: Adoption, Improved Potato Varieties, Hurdle Poisson

\section{Introduction}

Agriculture remains the main economic sector in Malawi and contributes significantly to the national development. It is a sector that receives high priority and attention from the Malawian Government. Its importance stems from the fact that it accounts for about 35-40 percent of the Gross Domestic Product (GDP), providing employment to about 84.5 percent of the labour force, contributes to over 90 percent of the export earnings and accounting for 82.5 percent of the foreign exchange earnings [1].
Population growth in Africa is occurring more rapidly than other regions of the world according to a report by AFIDEP [2] and this means the agricultural products and food demand in general is also increasing. The increase in per capita incomes, higher urbanization and the growing numbers of women in the workforce stimulate greater demand for highvalue commodities, processed products and ready-prepared foods [3]. Since agribusiness sector is an important catalyst for the development of efficient value chains, a contributor to improved product quality and safety and a provider of services that allow food to flow from production to consumption as reported by Gabor [4] then, as the rural 
inhabitants who are connected to infrastructure adopt more urbanized lifestyles, food consumption is becoming both more varied and more similar around the world [5]. To reduce the ever-increasing demand for food due to soaring population, there is a need to promote cultivation of short maturing crops like potato.

Potato (Solanum tuberosum L.) is the fourth most important food crop in Malawi, after maize, cassava and sweet potato. The crop plays a significant role in human nutrition and is number one non-cereal crop. The market for potato is expanding rapidly today because of urbanization. This growing domestic market presents a valuable livelihood opportunity for smallholder farmers besides benefiting vulnerable low-income consumers. Despite the growing market, smallholder farmers fail to realize the potential benefits from the product because of low quantities and quality of potato. The major constraints of potato production in Malawi include inadequate supply of reasonably priced, farmer- preferred, quality seeds, continuous use of poor planting materials, low value addition, inadequacies of transport and cold storage facilities.

The potential of potato for economic growth and poverty reduction is that it is largely grown by smallholder producers, thus increasing the chances that improvements in the potato sector, benefits directly poor rural households. As potatoes are relatively easy to market and its consumption is increasing worldwide, improved potato production techniques have the potential to simultaneously increase cash income of rural producer households and to directly contribute to increase household food security [6]. Potatoes also have the potential to double current yield of 15 tons/ha with good quality improved seed, improved farming practices and improved varieties.

Although productivity of potato in Malawi still falls short of the achievable yield (41 tons/ha), production has significantly increased over the past five years from 745, 262 tons in 2010 to $1,185,737$ tons in 2016. One of the major factors contributing to low potato productivity is the continuous use of poor quality planting materials especially in districts not yet empowered on use of on-farm seed improvement techniques.

To understand the reason that contributes to low usage of modern varieties by farmers, a study by Doss emphasized on the importance of conducting adoption studies so that results obtained should be channelled to the respective stakeholders in the seed systems [7]. Several adoption studies have been conducted in Malawi and other countries on different crops to establish the reasons that influence a farmer to adopt modern farming technologies. For instance, Chirwa [8] studied adoption of fertiliser and maize in Malawi, Kormawa et al. [9] studied adoption of improved cowpea varieties in Nigeria, Paudel and Matsuoka [10] studied adoption of improved maize varieties in Nepal, and Namwata et al. [11] studied adoption of (Irish) potatoes in Tanzania found out that farmers are more likely to adopt and use technologies that are user friendly and more so that are compatible with their existing environment but above all technologies that meet expectations and characteristics of the farmers. This paper therefore seeks to identify the underlying factors that influence smallholder farmers to adopt improved potato varieties in Malawi.

\section{Theoretical Framework}

Adoption model has been studied by making use of various theories coined by several scholars. For instance, Rodgers [12] came up with the popular innovation decision model that shows the process through which an individual (or other decision-making unit) passes from first knowledge of an innovation to forming an attitude towards the innovation, to a decision to adopt or reject, to implement of the new idea, and to confirmation of this decision. Diffusion is the process by which an innovation is communicated through certain channels overtime among the members of a social system [12]. When new ideas are invented, they are diffused and adopted or rejected. We use the concept of diffusion in our study in terms of understanding how many farmers know and use the technology.

The second model is the economic constraint outlined by a study of Adesina and Zinnah [13] that contends that economic constraints reflected in asymmetrical distribution patterns of resource endowments are the major determinants of observed adoption behavior. Lack of access to capital or land could significantly constrain adoption decisions. While attempts have been made to assert the 'superiority' of the economic constraint model over the innovation-diffusion model such conclusions have been challenged [13].

The third one is the adopter perception model by Kivlin and Fliegel [14] that suggests that the perceived attributes of innovations condition adoption behavior. The limited quantitative studies that have considered farmers' perceptions in the context of adoption decisions have included a perception variable - measuring farmers' perception of a problem (e.g. soil erosion) - in their models. However, by being concerned primarily with only the farmers' perceptions regarding the severity of the problem to be solved, the studies implicitly take the technical innovations (designed to solve the problem) as appropriate for farmers [13]. In the context of potato some of the perceived attributes include; tuber size, yield, cooking time that the variety takes, and skin color.

This study adopted the approach of combining adopter perception model and the economic constraint to look at how these influences adoption of improved potato varieties in Malawi.

The adoption decision can be modeled as a dichotomous choice of whether to adopt a new technology or not to adopt. Since this variable can take on only two values: 1 and 0 (adopt or not adopt), a binary choice model is used to analyze this adoption decision. Assumptions underlying binary choice models are that: (1) the economic agent is faced with a choice between two alternatives e.g. to adopt or not adopt; and (2) the choice the agent makes will depend on his/her attributes or characteristics [15]. The conceptual framework is then to build a model that will predict the adoption 
decision of an economic agent with given attributes. The utility maximization framework can be used to motivate this binary choice model. A household's adoption choice is based on whether the expected net utility derived from adopting the new technology is greater than from not adopting. For a new crop species, a household chooses between whether or not to plant the new crop in order to maximize their utilization of the land. Adoption is treated as an investment choice, where the farm household is seeking to maximize agricultural profit in relation to a chosen set of inputs and outputs. The decision whether to adopt or not is based on whether the new technology will bring more utility to the farm household than the current technology.

\section{Methodology}

\subsection{Definition of Adoption and Conceptualization}

Agricultural research focuses on developing new technologies to improve agricultural productivity and farmers' well-being. The rapid adoption of new agricultural technologies in developed and some developing countries has increased agricultural productivity, contributed to overall economic growth, and reduced food insecurity and poverty $[16,17]$. The definition and conceptualization of agricultural technology adoption varies among experts. In their study of adoption of agricultural technology in developing countries, Feder et al. [18] conceptualize adoption of agricultural technologies at two different levels: aggregate and individual (farm-level) adoption. They define aggregate technology adoption and diffusion as the process of the spread of a new technology within a region. Aggregate adoption is measured at the population level, rather than at the individual level. In contrast, the authors define individual adoption as the degree of use of a new technology in long-run equilibrium, when the farmer has full information about the new technology and its potential.

Several studies $[13,19,8,7]$ carried on adoption usually start by defining adopter and proceed by outlining some of the likely factors that affect adoption. However, it is worth noting that the definition of adopter varies across studies. For instance, Doss [7] reported that the definition of adopter varies widely even across the 22 studies that the International Centre for Wheat and Maize Improvement (CIMMYT) conducted in East Africa examining the adoption of improved varieties of wheat and maize and fertilizer. In defining "adoption" the first thing is to consider whether adoption is a discrete state with binary variables or whether adoption is a continuous measure. Many studies use a simple dichotomous variable approach. There is a distinction that is made between discrete and continuous technology adopters among typical farmers who use either unimproved or improved inputs. A farmer is classified as an adopter if he/she is found to be cultivating improved varieties or using modern technologies. With respect to the adoption of improved varieties, discrete adoption refers to a farmer who stops using a local (traditional) variety and adopts an improved variety.
In contrast, continuous adoption refers to situations where farmers increasingly planting more land to improved varieties, while continuing to grow some local varieties. Thus, a farmer may be classified as an adopter and still grow some local varieties [20]. Furthermore, Doss [7] emphasizes that defining agricultural technological adoption is complex. Studies carried out by CIMMYT [5] have used several different adoption definitions to distinguish between, for example, varieties that were originally introduced as improved hybrids, but have been repeatedly recycled (e.g., farmers plant seed from a previous harvest) versus planting new certified seeds. The author also argues that it is necessary to distinguish between farmers who continue to use a newly adopted technology from those who discontinue using it. The rate of adoption is defined as the percentage of farmers who have adopted a given technology. On the other hand, the intensity of adoption is defined as the level of adoption of a given technological package. Put it in a different way, the number of hectares planted with improved seed also tested as (the percentage of each farm planted to improved seed) or the amount of input applied per hectare represent the intensity of adoption of the respective technologies [21].

This study adopted the approach of estimating adoption as a dichotomous variable where a farmer is classified as adopter or non-adopter. Because of several varieties of potato that are currently grown by smallholder farmers in Malawi, there are a number of varieties that have been categorized as improved and as such farmers are classified as being adopters if they indicate to have grown any of the improved varieties and otherwise classified as non-adopters. Specifically, if a farmer reported to have grown any of the following (Mwai, Thandizo, Chuma and Zikomo) potato varieties is considered to be an adopter and non-adopter otherwise.

\subsection{Empirical Model Specification}

Farmers' decision to adopt or not to adopt a technology is assumed to be the outcome of a complex set of factors related to the farmers' objectives and constraints. In other words, there are certain factors - including market forces, social, institutional, and management factors that affect the likelihood that farmers adopt a technology. Thus, if each farmer and each technology can be classified based on a core set of variables, then it is possible that the probability of a farmer adopting that technology could be estimated. As earlier indicated in the theoretical model, the study considers binary dependent variable, $\mathrm{Y}_{\mathrm{i}}$ to model adoption where it takes the value of 1 if the farmer was found to be growing any of the improved potato varieties and 0 if otherwise. It further assumes that the probability to adopt improved potato variety is influenced by a set of demographic characteristics, economic and institutional factors. For the second hurdle (truncated model), improved variety adoption becomes continuous and the dependent variable is the number of improved potato varieties grown by a household.

The household characteristics deemed to influence 
improved potato adoption in this study include household heads characteristics (age, experience in potato production, gender and education) and household size. The conventional approach to adoption study considers age to be negatively related to adoption based on the assumption that with age farmers become more conservative and less amenable to change. On the other hand, it is also argued that with age farmers gain more experience and acquaintance with new technologies and hence are expected to have higher ability to use new technologies more efficiently. Education normally is expected to have positive relationship with adoption as it believed to enhance the allocative ability of decision makers (farmers) by enabling them to think critically and use information sources effectively. However, just as Doss et al. [22] reported, education in this study is not expected to have strong effects on adoption because potato is not a new technology.

Institutional and economic factors considered important in this study include access to extension that has been proxied by number of visits by extension agents reported by a household during the study period, membership to any farmer-based clubs or associations, distance to the nearest market, participation in farmer/producer training and farm size owned by the household. The size of landholding is expected to be positively correlated with adoption of improved potato varieties, as farmers with bigger farms are assumed to have the ability to purchase and multiply improved potato seed and the capacity to bear risk if the technology fails and have adequate land for the different varieties [18]. Exposure to information reduces subjective uncertainty and, therefore, increases likelihood of adoption of new technologies [20]. Extension and club membership are thus expected to have a positive correlation with adoption. Distance to the market is expected to have a negative correlation with adoption as longer distances reduces the likelihood of adoption because of the transportation costs that farmers will have to incur in going to purchase inputs.

Technology specific attributes were captured using dummies because of the limitation in the way data was collected. Farmers were asked to indicate whether the character was an important attribute or not compared to the traditional varieties. The study managed to pick and use three top characteristics indicated by household which are maturity, tuber size and yield.

\subsection{The Double Hurdle Model}

This study extends the conventional adoption decision modeling of looking at the factors influencing adoption decision by looking further at the factors that influence the number of varieties that a farmer grows. This modeling requires the use of count models of which the most commonly used are the Poisson, Negative Binomial and Hurdle Poisson. Poisson model is the simplest and perhaps the most common method for count variables and it is the model that is derived from the Poisson distribution by parameterizing the relation between the mean parameter and covariates (regressors) [23]. One of the assumptions of Poisson models is the equidispersion which implies equality of mean and variance and once this assumption is violated it results in overdispersion or underdispersion which is usually common with zero-inflated data [23]. The authors further highlighted that this assumption is similar to homoscedasticity ${ }^{1}$ under the ordinary least square and as such statistical test for overdispersion is highly required after running a Poisson model. Presence of overdispersion results in impacts such as invalid conclusions, inaccurate t-statistics and inaccurate standard errors [23]. One frequent manifestation of overdispersion is that the incidence of zero counts is greater than expected for the Poisson distribution and this is of interest because zero counts frequently have special status. An alternative model that can address the problems associated with standard Poisson models is the Negative Binomial model (NB2). However, although this model takes care of the problem of overdispersion, it has another weakness in that it does so without knowledge of the possible reason for overdispersion and also it is not ideal for data that has a larger number of zeros [23]. To address the shortfalls of the two models, Hurdle models are usually used. Hurdle models are based on the assumption that zero counts are generated from a different process than are the positive counts in a given data situation. This study used Hurdle instead of the standard Poisson or the Negative Binomial because the count data has a lot of zero (about 27 percent). In order to capture the sequential binary choice decision, a hurdle model or two-part model is applied. A hurdle model has the interpretation that it reflects a two-stage decisionmaking process. Originally formulated by [24], the doublehurdle model assumes that households make two sequential decisions with regard to adopting and intensity of use of a technology. Each hurdle is conditioned by the household's socio-economic characteristics. In the double-hurdle model, a different latent variable is used to model each decision process.

The decisions to adopt improved potato variety and subsequently plant a number of improved varieties over time are examined using a hurdle count model [25]. Hurdle models are typically applied to attend to problems arising from sample selection bias and the discrete, non-negative nature of the outcome (i.e., the number of improved potato varieties a farmer reported to have planted). In the study, a producer must have grown potato as a crop to answer the question: how many improved varieties did the farmer planted during the previous growing season? Thus, the first stage of the model (the "hurdle") explains the decision to adopt improved potato variety using a logit regression that models the adoption decision $(1=$ yes, $0=$ no $)$ to use improved potato varieties. Given the decision to adopt improved potato variety (a binary outcome), the number of varieties grown (a positive, discrete variable; $k=1,2, \ldots, K$ ) is subsequently modeled using a Poisson regression. The hurdle model is widely used, and the hurdle negative

1 The error term has a constant variance 
binomial model is quite flexible.

Farmers usually make rational decisions when it comes to adoption of any particular technology. Since the objective of the farmer is to maximize expected (discounted) profits over time horizon subject to input and commodity prices and technology constraint, farmers will usually weigh the benefits associated with a particular technology before they decide to adopt. Rationally a farmer will adopt a technology if the expected (discounted) utility of profits of using that technology is greater than utility from the old technology [19].

The Poisson model is the simplest and perhaps the most common method for modeling counts variables [23]. The Poisson probability distribution is given as

$$
\begin{gathered}
\operatorname{Pr}(Y=y)=\frac{\exp (-\mu) \mu^{y}}{y !}, y=0,1,2 \ldots, \quad, \quad(1) \\
f(y \mid \mu, \alpha)=\frac{\Gamma\left(y+\alpha^{-1}\right)}{\Gamma(y+1) \Gamma\left(\alpha^{-1}\right)}\left(\frac{\alpha^{-1}}{\alpha^{-1}+\mu}\right)^{\alpha^{-1}}\left(\frac{\mu}{\alpha^{-1}+\mu}\right)^{y}, \\
\alpha \geq 0, y=1,2,3 \ldots
\end{gathered}
$$

where $\mathrm{Y}$ is the number of potato varieties grown by the household and $\mu$ is mean parameter. The Poisson regression model is derived from the Poisson distribution by parameterizing the relation between the mean parameter $\mu$ and covariates (regressors) $\mathrm{x}$. The standard specification for the mean parameter is $\mu=\exp (\mathrm{x} \beta)$, where $\beta$ is a vector of the unknown parameters. In applications, however, the Poisson model is usually restrictive. In particular, it imposes the restriction that the mean and variance are equal, but for most observed count data, the variance usually exceeds the mean, a feature called overdispersion. This makes the Poisson model deficient.

A common alternative to the Poisson model in case of over dispersion is the negative binomial model which is given as where the function $\Gamma($.$) is the is the gamma function.$

However, both the Poisson and negative binomial models are not suitable for data with excess of zero [23]. This is the case with data used in this study. The 300 households used in this study were potato farmers who were growing potato and they include those growing traditional varieties and those growing improved. In this case, the zeros are coming from households that grew potato but did not grow improved varieties due to other factors like preference of traditional varieties or lack of access to seed of improved varieties. From the study about twenty seven percent of the sample households did not grow improved potato varieties during the study period.

To handle data sets that contain excess zero, two-part models have been used, with the hurdle Poisson and Zero Inflated Poisson (ZIP) models being the common ones. Each of these two models consists of an equation for participation and a model for the event count that is conditioned on the outcome of the first decision [25].

The hurdle Poisson model combines a binary model (participation part) to predict zeros and a zero-truncated Poisson model (count part) to predict non-zero counts [23]. In this way, the hurdle Poisson relaxes the implicit assumption in the Poisson and the negative binomial models that the zeros and the positives come from the same data generating process. The advantages of using a hurdle Poisson are two-fold; firstly, the hurdle Poisson model is suitable for taking into account the overdispersion or underdispersion of the data [23]. Secondly, hurdle Poisson model controls for data selection.

The starting point of the hurdle Poisson model is a binary process, which determines whether the variable takes on the value zero or a positive value [24]. The probability mass function is given as;

$$
\operatorname{Pr}(Y=y)= \begin{cases}\pi, & y=0 \\ 1-\pi & \mathrm{y}=1,2,3, \ldots\end{cases}
$$

The zero-truncated Poisson process has probability mass function;

$$
\operatorname{Pr}(Y=y \mid Y \neq 0)= \begin{cases}\frac{\lambda^{y}}{\left(e^{\lambda}-1\right) y !}, & \mathrm{y}=1,2,3, \ldots \\ 0, & \text { otherwise }\end{cases}
$$

This gives the following unconditional mass function for Y;

$$
\operatorname{Pr}(Y=y)=\left\{\begin{array}{lc}
\pi, & y=0 \\
(1-\pi) \frac{\lambda^{y}}{\left(e^{\lambda}-1\right) y !}, & \mathrm{y}=1,2,3, \ldots
\end{array}\right.
$$

The log likelihood for the $\mathrm{t}^{\text {th }}$ observation, assuming the observations are independently and identically distributed, is

$$
\ln \mathrm{L}\left(\pi_{i}, \lambda_{i}, y_{i}\right)= \begin{cases}\ln \left(\pi_{i}\right), & y=0 \\ \ln \left\{(1-\pi) \frac{\lambda^{y}}{\left(e^{\lambda}-1\right) y !}\right\}, & \mathrm{y}=1,2,3, \ldots\end{cases}
$$

Therefore, the log likelihood function of the hurdle Poisson can be viewed as the sum of the log likelihoods from two separate models: a binomial probability model and a truncated-at-zero Poisson model. As such, the hurdle model 
log likelihood can always be maximized, without loss of information, by maximizing the two components separately. This feature allows estimation of the hurdle Poisson model in two separate steps. In the first step, binomial probability model is estimated followed by truncated Poisson model [26].

Zero-inflated Poisson model provides another way to model excess zeros. In ZIP regression, the counts $Y_{i}$ equal 0 with probability $\varphi_{i}$ and follow a Poisson distribution with mean $\mu_{i}=\mu(\mathrm{x}, \beta)$ with probability $1-\varphi_{i}$. The probability mass function for the zero-inflated Poisson is given as

$$
\operatorname{Pr}(Y=y)=\left\{\begin{array}{lc}
\varphi_{i}+\left(1-\varphi_{i}\right) \exp \left(-\mu_{i}\right), & y=0 \\
\left(1-\varphi_{i}\right) \frac{\exp \left(-\mu_{i}\right) \mu_{i}^{y}}{y !} & \mathrm{y}=1,2,3, \ldots
\end{array}\right.
$$

The probability $\varphi_{i}$ is parameterized as a logistic function of the observable vector of covariates $z_{i}$, thereby ensuring nonnegativity of $\varphi_{i}$, that is

$$
\varphi=\frac{\exp \left(\mathbf{z}_{i} \alpha\right)}{1-\exp \left(\mathbf{z}_{i} \alpha\right)}
$$

where $\mathrm{z}_{\mathrm{i}}$ is a vector of covariates while $\alpha$ is a vector of coefficients. Let $1\left(y_{i}=0\right)$ denote an indicator variable that takes value 1 if $y_{i}=0$, and zero otherwise. The loglikelihood function for the double hurdle model is:

$$
\log L=\sum_{0} \ln \left[1-\emptyset\left(Z_{i}^{\prime} \alpha\right) \emptyset\left(\frac{x_{i}^{\prime} \beta}{\delta}\right)\right]+\sum \ln \left[\varnothing\left(Z_{i}^{\prime} \alpha\right) \frac{1}{\delta} \emptyset\left(\frac{y_{i}-x_{i}^{\prime} \alpha}{\delta}\right)\right](9)
$$

Empirical results by both [24] and [30] reveal that the double-hurdle model gives superior results to those obtained from Tobit model. Thus, in this study we estimated the decision to adopt improved potato variety and the intensity of adoption (number of improved varieties grown) using a double-hurdle model.

After adoption, the producer decides how many improved potato varieties to grow in a particular season. Because the choice set is observed as number of varieties (a discrete, countable decision), the decision is appropriately modeled using a count regression model such as the Poisson or negative binomial models [25]. The model was estimated using full information maximum likelihood estimation (FIML). Maximum likelihood estimation of the hurdle model involves separate maximization of the two terms in the likelihood, one corresponding to the zeros and the other to the positives. This is straightforward [25]. The statistical software program STATA 11 was used to run the model with the help of the STATA user written program hplogit. A heteroskedastic robust covariance matrix was estimated using the survey weights as reported by Wooldridge [27], which was subsequently used to make inferences about the covariates explaining adoption of improved potato varieties.

\section{Results and Discussion}

Table 1 presents coefficients and standard errors (in parenthesis) results from the Hurdle Poisson model of improved potato varieties adoption. The results of the model are presented in two ways, firstly the participation part where the farmer decides to adopt improved potato variety or not and then the second part of the model where a decision is made on how many of the improved varieties to grow. The results of the model show that amongst the household socio-economic characteristics that were included in the model, age of the household head, experience in potato farming and farm size were significant at 5 percent level of significance showing that they have an influence on the farmers decision to adopt improved potato varieties whilst education level and sex, although positively related with adoption do not significantly influence the decision to adopt. Further to this it is also clear from the results that amongst the institutional factors that were hypothesised to influence adoption, extension, market distance and participation in farmer/producer training are significant factors that influence a farmer to adopt improved potato varieties just like the technology specific variables such as tuber size, yield and earliness to maturity. However, the second decision on how many varieties to adopt is influenced by age of the household head, size of land holding, access to information that was proxied by the number of extension visits, participation in a training and by the yielding potential of the variety.

Table 1. Hurdle Poisson regression results of the factors influencing adoption of improved potato varieties.

\begin{tabular}{lll}
\hline \multirow{2}{*}{ Variable } & Logit (Deciding to Adopt or not) & Poisson (Number of varieties grown \\
\cline { 2 - 3 } & Coefficient (Robust std errors) & Coefficient (Robust std errors) \\
\hline Age & 0.027 & $0.206^{* *}$ \\
& $(0.090)$ & $(0.089)$ \\
Age $^{2}$ & -0.001 & $-0.002^{* *}$ \\
Education & $(<0.001)$ & $(0.001)$ \\
& 0.056 & -0.058 \\
Sex & $(0.056)$ & $(0.058)$ \\
Household size & 0.422 & 0.040 \\
Experience & $(0.545)$ & $(0.497)$ \\
& -0.183 & -0.068 \\
& $(0.104)$ & $(0.085)^{* *}$ \\
\hline
\end{tabular}




\begin{tabular}{lll}
\hline \multirow{2}{*}{ Variable } & Logit (Deciding to Adopt or not) & Poisson (Number of varieties grown \\
\cline { 2 - 3 } & Coefficient (Robust std errors) & Coefficient (Robust std errors) \\
\hline \multirow{3}{*}{ Land size } & $(<0.001)$ & $(0.03)$ \\
& $0.603^{* *}$ & 0.041 \\
Extension & $(0.211)$ & $(0.125)$ \\
& $0.006^{* *}$ & $0.004^{* *}$ \\
Club & $(0.003)$ & $(0.002)$ \\
& 0.027 & 0.478 \\
Market & $(0.407)$ & $(0.427)$ \\
& $-0.157^{* *}$ & 0.077 \\
Training & $(0.070)$ & $(0.056)$ \\
& $1.178^{* *}$ & -0.280 \\
Yield & $(0.433)$ & $(0.379)$ \\
& $1.029^{* *}$ & $1.137^{* *}$ \\
Tuber size & $(0.392)$ & $(0.510)$ \\
& $1.889^{* *}$ & 0.335 \\
Maturity & $(0.711)$ & $(0.488)$ \\
Constant & $1.370^{* *}$ & -0.290 \\
& $(0.456)$ & $(0.371)$ \\
\hline
\end{tabular}

Source: Computed from study data

Note: $* *(p$-value $<0.05)$

Table 2 presents the odds ratios and standard errors (in parenthesis) and Incidence rate ratios (IRR) and standard errors (in parenthesis) results of the hurdle Poisson model. In case of land, the results show that a unit increase in land size owned by a farmer increases the odds of adopting improved potato variety by 1.8 whilst a unit increase in the number of visits by extension agents increases the odds of farmers adopting improved potato variety by 1 . As expected, distance to market center has also a negative and significant relationship (at 5 percent level of significance) with probability of adoption of improved potato varieties. The odds-ratio of 0.9 for market distance implies that other things being kept constant, the odds-ratio in favor of adopting improved potato varieties decreases by a factor of 0.9 as the market distance increase by one kilometer. The results further show that participating in farmer/producer trainings have an influence on the decision to adopt and on the number of varieties to grow. For instance, farmers who attended potato production trainings increases the odds of adopting by a probability of about 3 . In terms of variety specific attributes, the results show that varieties that are higher yielding, having bigger tubers and mature earlier have a higher odds $(3,7$ and 4 respectively) of being adopted. Detailed results and interpretation of the double hurdle Poisson model for the 8 significant variables on adoption are presented in the following paragraph.

Table 2. Odds ratio and Incident Rate Ratio of the factors influencing adoption of improved potato varieties.

\begin{tabular}{lll}
\hline \multirow{2}{*}{ Variable } & Logit (Deciding to Adopt or not) & Poisson (Number of varieties grown \\
\cline { 2 - 3 } & Odds ratio (Robust std errors) & IRR (Robust std errors) \\
\hline Age & 1.027 & $0.206^{* *}$ \\
& $(0.092)$ & $(0.089)$ \\
age $^{2}$ & 1.000 & $-0.002^{* *}$ \\
Education & $(0.001)$ & $(0.001)$ \\
& 1.058 & -0.058 \\
Sex & $(0.059)$ & $(0.058)$ \\
Household size & 1.526 & 0.040 \\
& $(0.831)$ & $(0.497)$ \\
Experience & 0.833 & -0.068 \\
& $(0.087)$ & $(0.085)$ \\
Land & 1.000 & 0.02 \\
& $(0.001)$ & $(0.009)^{* *}$ \\
Extension & $1.827^{* *}$ & 0.041 \\
& $(0.385)$ & $(0.125)$ \\
Club & $1.006^{* *}$ & $0.004^{* *}$ \\
Market & $(0.003)$ & $(0.002)$ \\
\hline
\end{tabular}




\begin{tabular}{lll}
\hline \multirow{2}{*}{ Variable } & Logit (Deciding to Adopt or not) & Poisson (Number of varieties grown \\
\cline { 2 - 3 } & Odds ratio (Robust std errors) & IRR (Robust std errors) \\
\hline \multirow{3}{*}{ Training } & $(0.060)$ & $(0.056)$ \\
& $3.248^{* *}$ & -0.280 \\
Yield & $(1.405)$ & $(0.379)$ \\
& $2.797^{* *}$ & $1.137^{* *}$ \\
Tuber size & $(1.097)$ & $(0.510)$ \\
& $6.616^{* *}$ & 0.335 \\
Maturity & $(4.701)$ & $(0.488)$ \\
& $3.935^{* *}$ & -0.290 \\
\hline
\end{tabular}

Source: Computed from study data

Note: $* *(p$-value $<0.05)$

The positive sign on the coefficient of age show that there is a positive correlation between age and adoption. However, age appears to have a significant impact on the second decision level especially when a farmer is deciding how many of the improved varieties to grow, i.e. showing that age does not matter at the extensive margin but rather at the intensive margin. In other words, this means that age has minimal influence on the decision of whether to grow improved potato varieties but rather have more influence on the number of improved to be grown. The implication of this is that as farmers are aging they tend to gather experience with the crop and as such realizes the benefits associated with it hence they are able to grow a number of varieties. This is the same reason why the results show a positive and significant influence of experience in potato production has over adoption decision. Similar results were reported by Cornejo and McBridgie [17] where it was argued that experience with technology is one of the critical factors that determines the number of technology that a farmer will adopt, and this is usually captured by age of the farmer in situations where information on the period since the farmer started cultivating the crop is not known.

The odds-ratio in favor of adopting improved potato varieties, other factors kept constant increases by a factor of 1.8 as land increases by one unit. This implies that a farmer who has more land will be more likely to adopt improved potato varieties. The implication for this is that farmers with more land should not be ignored when promoting cultivation of improved varieties as they are the ones that are likely to adopt. Several studies have reported similar findings for instance, Adesina and Zinnah [13] argued that farmers with larger farm size are more likely to adopt agricultural technologies because they are able to bear the risk associated with trying new things because of land area where they can diversify by growing a number of crops, Doss et al. [22] reported that households with larger farm size adopts improved varieties because they usually have better access to credit and information that have been widely documented to influence adoption.

The positive coefficient on extension indicates that there is positive and significant (at 5 percent) relationship between adoption of improved potato varieties and access to information that has been proxied by the number of contacts with extension agents. This implies that potato farmers with access to information through contacts with extension workers are the ones who are more likely to adopt improved varieties. Access to information is significant both at the first (deciding to adopt improved potato varieties or not) and second (deciding how many varieties to grow) decision level indicating that information plays a crucial role in decision making by farmers just as reported by Feder et al [18] where it was argued that farmers who have access to information about a particular technology are more likely to adopt. The implication of this finding is that extension should really be intensified to promote the adoption of improved potato varieties. Similar findings were also reported by a number of scholars like Chirwa [8] argued that farmers with access to information through extension services adopt modern technologies faster because they are well informed about the advantages associated with modern technologies as such they make informed decisions based on the information given. Extension visits have a positive influence on adoption because farmers are exposed to new technologies and in the process get convinced to adopt them [28].

The results have shown that there is a negative but significant relationship between adoption and the distance to the nearest market. This implies that as the distance to the nearest market increases/reduces the probability of farmers adopting improved varieties is reduced/increased hence showing that farmers who are close to the markets are more likely to adopt improved potato varieties. The results concur with what was found in the studies conducted by Paudel and Matsouka [10], Namwata et al. [11] and Kabuli [29]. Farmers closer to markets adopt improved technologies because they do not have to travel long distance with their produce to sell hence incur no costs on transport unlike those that are far and have bulky and a lot of harvest [29]. In the case of potato, being partly a cash crop entails that farmers have to think of the markets where they will sell their crop once it matures and as such there is higher likelihood that farmers closer to the market will adopt improved varieties because they have access to market. Farmers closer to markets have higher probability of adopting improved varieties because they have access to information about the availability of market and also prices prevailing on the market and this informs the farmers when deciding what to grow for the next growing season [11]. 
Distance to the market is an important determinant of adoption for farmers producing bulky commodities because of transportation and infrastructure challenges [10]. Poor infrastructure like roads raises transportation costs and as such farmers closer to markets are more likely to adopt improved technologies of bulky crops like potato.

Participation in training for potato farmers/producers was also positively and significantly correlated to adoption of improved potato varieties. The estimated coefficient for the dummy variable indicating households' participation crop production training reveal the positive and significant impact of this variable on the adoption decision of potato technologies in the study area. The plausible reason is that, farmers who participated in training sessions are most likely to produce the crop in significant amount because training might have helped farmers to create awareness and promote the understanding about the merits of the available information concerning the crop.

Yielding potential had positive and significant influence on adoption of improved potato varieties at 5 percent level of significance. Similar results were also obtained for the other variety specific characteristics like earliness to maturity and the tuber size of the variety. The results implies that farmers are likely to adopt potato varieties that are high yielding, early maturing and having a bigger tuber sizes. The results are like what a study by Adesina and Zinnah [13] found where they argued that technologies that meet the characteristics that farmers look for when selecting a particular crop variety have higher probability of being adopted. The report further reveals that some of the characteristics are usually associated with individual's perceptions for instance attribute like taste is very subjective as what is pleasing to a single farmer may not please everyone. Adesina and Forson [19] argued that technologies that raise agricultural production like improved varieties and fertilizer have higher probability of being adopted because of the problem of land sizes. The report ague that most developing countries have land problem as a challenge due to higher population and as such the only way farmers increases output is to adopt technologies that are higher yielding, and resistant to drought (early maturing) which is another serious problem in developing countries.

\section{Conclusion and Policy Recommendations}

In general, the study concluded that socio-economic factors such as age of the household head, experience in potato production and land size significantly influence farmers' decision to adopt improved potato varieties in the study areas. Institutional factors such as access to extension services, distance to the nearest market and participation in farmer/producer trainings are very important determinants of adoption of improved potato varieties. The study further found that variety specific characteristics like earliness to maturity, higher yielding and larger tuber size are preferred significant attributes that influence a farmer to adopt improved potato variety. The study also indicated that the decision to adopt a number of varieties is influenced by age of the household head, experience in potato farming, access to information (access to extension services) and the yielding potential of the variety. However, the study found that certain farm level characteristics and socio-economic factors such as club membership, gender, total household income, education, and household size do not influence the adoption decision at household level.

To increase adoption of recommended potato production practices, it was recommended that extension agents should be adequately involved in disseminating these production practices by using open field days, demonstration and control plots so as to encourage farmers in adopting the production practices. Secondly, the study also recommended that Government and other stakeholders need to also invest in extension service in sensitizing potato farmers in key potato production areas especially on production practices that have potential to increase level of adoption as well as farmer's productivity and income.

\section{References}

[1] Agriculture Sector Wide Approach, ASWAP. (2010). Support to the implementation of the agriculture sector wide approach and the Green Belt Initiative (GBI). Malawi Government.

[2] African Institute for Development Policy (AFIDEP) (2012). Population, Climate Change, and Sustainable Development in Africa: [http://pai.org/wp-content/uploads/2012/06/PAIAFIDEP.pdf] site visited on 20/3/2015.

[3] FAO and UNIDO (2009). Agro-industries for development: Edited by Carlos A. da Silva and Doyle Baker: Printed and bound in the UK by the MPG Books Group, Bodmin. Published jointly by CAB International and FAO: CABI Head Office: No worthy Way: Wallingford: Oxford shire OX10 $8 \mathrm{DE}, \mathrm{UK}$.

[4] Gabor, K., Carlos, A., da Silva and Nomathemba, M. (2013). Enabling environments for Agribusiness and Agro-industries Development: Regional and country perspectives: ISBN 97892-5- 107410-7: Publishing Policy and Support Branch, Office of Knowledge Exchange, Research and Extension, FAO, VialedelleTerme di Caracalla, 00153 Rome, Italy, $71 \mathrm{pp}[\mathrm{http}: / / \mathrm{www}$. fao.org/] Site visited on 31/10/2016.

[5] CIMMYT Economics Program, (1993). The adoption of agricultural technology. A guide for survey design. Mexico, D. F.: CIMMYT.

[6] Gildemacher, P. R. 2012. Innovation in Seed Potato Systems in Eastern Africa. Submitted in fulfillment of the requirements for the degree of doctor at Wageningen University.

[7] Doss, C. R. (2006). Analysing technology adoption using microstudies. Limitations, challenges, and opportunities for improvement. Agricultural Economics 34: 207-219.

[8] Chirwa, E. W. (2005). Adoption of fertiliser and hybrid seeds by smallholder maize farmers in southern Malawi. Development Southern Africa Vol. 22, No. 1. 
[9] Kormawa, P. M., Ezedinma, C. I. and Singh B. B. (2004). Factors Influencing Farmer-to-Farmer Transfer of an Improved Cowpea variety in Kano State, Nigeria. Journal of Agriculture and Rural Development in the Tropics and Subtropics Volume 105, No. 1, 2004, pages 1-13.

[10] Paudel, P. and Matsuoka, A. (2008). Factors Influencing Adoption of Improved Maize Varieties in Nepal: A Case Study of Chitwan District. Australian Journal of Basic and Applied Sciences, 2(4): 823-834.

[11] Namwata B. M. L., Lwelamira, J. and Mzirai, O. B. (2010). Adoption of improved agricultural technologies for Irish potatoes (Solanum tuberosum) among farmers in Mbeya Rural district, Tanzania: A case of Ilungu ward. Journal of Animal \& Plant Sciences. Vol. 8, Issue 1: 927- 935.

[12] Estrada, J. M. (2004). Regional overview of the soybean markets: Challenges and opportunities for smallholder farmers in Southern Africa Study commissioned by the International Institute for Tropical Agriculture (IITA).

[13] Adesina, A. A and Zinnah, M. M. (1993). Technology characteristics, farmers' perceptions and adoption decisions: A Tobit model application in Sierra Leone. Agricultural Economics, 9: 297-311.

[14] Kivlin, J. E. and Fliegel, F. C. (1966). Attributes of innovations as factors in diffusion. American Journal of Sociology, 72: 235-248.

[15] Pattanayak, S. K., Mercer. D. E., Sills, E. and Yang, J. C. (2003). Taking Stock of Agroforestry Adoption Studies. Agroforestry Systems 57:173-186. Kluwer Academic Publishers, Netherlands.

[16] Bandiera, O., and Rasul, I. (2005). Social Networks and Technology Adoption in Northern Mozambique. The Economic Journal 116(514): 869-902. Calcutta. pp. 65-72.

[17] Cornejo, J. F., and McBridge, W. D. (2002) Adoption of Bioengineered Crops. Agricultural Economic Report No. 810. Washington, DC 20036-583.

[18] Feder, G., R. Just, and Zilberman, D. (1985). Adoption of Agricultural Innovations in Developing Countries: A Survey. Economic Development and Cultural Change 33: 255-298. The University of Chicago Press.
[19] Adesina, A. A., and Forson, J. B. (1995). Farmers' Perceptions and Adoption of New Agricultural Technology: Evidence from Analysis in Burkina Faso and Guinea, West Africa. Agricultural Economics 13: 1-9.

[20] Doss, C. R. (2003). Understanding farm level technology adoption: Lessons learned from CIMMYT's micro surveys in Eastern Africa. CIMMYT economics working paper 03-07. Mexico, D. F.: CIMMYT.

[21] Nkonya, E., Schroeder, T. and Norman, D. (1997). Factors affecting adoption of improved maize seed and fertilizer in North Tanzania. Indian Journal of Agricultural Economics. 48(1):1-12.

[22] Doss, C. R., Wangi, M., Verkuijl, H. and De Groote, H. (2003). Adoption of Maize and Wheat Technologies in Eastern Africa: A Synthesis of the Findings of 22 Case Studies. CIMMYT Economics Working Paper 03-06. Mexico, D. F.: CIMMYT.

[23] Cameron, A. C., \& Trivedi, P. K. (1998). Regression analysis of count data. New York: Cambridge University Press.

[24] Cragg, J. (1971). Some Statistical Models for Limited Dependent Variables with Application to the Demand for Durable Goods. Econometrica 39:829-844.

[25] Cameron, A. C. and Trivedi, P. K. (2005). Microeconometrics: Methods and Applications. New York, NY: Cambridge University Press.

[26] McDowell A. (2003). From the Help Desk: Hurdle Models. The Stata Journal 3(2), 178-184.

[27] Wooldridge, J. 2004. Introductory Econometrics. Ohio: Thomson South-Western. York NY: Cambridge University Press.

[28] Umar, G. (2016). Factors influencing adoption of recommended Irish potato production practices in Kudan and Giwa local government areas of Kaduna state, Nigeria.

[29] Kabuli, A. (2005). Economic assessment of the benefits of soybean incorporation within smallholder maize-based cropping systems and factors affecting adoption in Malawi. MSc Thesis, Bunda College of Agriculture.

[30] Moffatt, P. G. (2003). Hurdle models of loan default. School of Economic and Social Studies University of East Anglia. 